\section{(6) OPEN ACCESS}

\title{
Study of Optimal Perimetric Testing in Children (OPTIC): evaluation of kinetic approaches in childhood neuro-ophthalmic disease
}

\author{
Dipesh E Patel, ${ }^{1,2,3,4}$ Phillippa M Cumberland, ${ }^{1,2}$ Bronwen C Walters, ${ }^{2,4}$ \\ Mario Cortina-Borja, ${ }^{5}$ Jugnoo S Rahi, ${ }^{1,2,3,4}$ For the OPTIC study group
}

\begin{abstract}
1 Life Course Epidemiology and Biostatistics, UCL Institute of Child Health, London, UK 2Ulverscroft Vision Research Group, London, UK ${ }^{3} \mathrm{NIHR}$ Biomedical Research Centre, Moorfields Eye Hospital NHS Foundation Trust and UCL Institute of Ophthalmology, London, UK

${ }^{4}$ Clinical and Academic Department of Ophthalmology, Great Ormond Street Hospital NHS Foundation Trust, London, UK

${ }^{5}$ Clinical Epidemiology, Nutrition and Biostatistics Section, UCL GOS Institute of Child Health, London, UK
\end{abstract}

\section{Correspondence to} Professor Jugnoo S Rahi, UCL GOS Institute of Child Health, LondonWC1N1EH, UK; j.rahi@ ucl.ac.uk

Received 23 May 2018 Revised 6 August 2018 Accepted 25 August 2018 Published Online First 19 September 2018

\section{ABSTRACT}

Aims We compared feasibility, quality and outcomes of visual field (VF) testing in children with neuro-ophthalmic disease between the discontinued 'gold-standard' Goldmann and Octopus perimeters.

Methods Children with neuro-ophthalmic disease, attending Great Ormond Street Hospital, London, were assessed using standardised protocols by one examiner in a single sitting, using Goldmann and Octopus kinetic perimetry. Outputs were classified to compare severity of loss and defect type. Test quality was assessed using both qualitative and quantitative methods.

Results Thirty children (40\% female) aged 5-15 years participated. Goldmann perimetry was completed in full by $90.0 \%$ vs $72.4 \%$ for Octopus. Inability to plot the blind spot was the most common reason for not completing testing. Over $75 \%$ completed a test in $\leq 20$ min. Duration was similar between perimeters (paired t-test, mean difference: $0.48 \min (-1.2,2.2), p=0.559)$. The lowest quality tests were for Octopus perimetry in children $<8$ years, without significant differences between perimeters in older children (McNemar's test, $\left.\chi^{2}=1.0, p=0.317\right)$. There was broad agreement between Goldmann and Octopus outputs (good quality, $\mathrm{n}=21$, Bland-Altman, mean difference for isopters $14 \mathrm{e}$ $\left(-514.3 \mathrm{deg}^{2}(-817.4,-211.2), \mathrm{p}=0.814\right)$, I2e $(-575.5$ $\left.\operatorname{deg}^{2}(-900.1,-250.9), p=0.450\right)$ and blind spot (20.8 $\left.\left.\operatorname{deg}^{2}(5.7,35.8), p=0.451\right)\right)$. However, VF severity grades and defect type matched in only $57 \%$ and $69 \%$ of tests, respectively. Octopus perimetry underestimated severe VF defects.

Conclusions Informative perimetry is feasible in children $\geq 8$ years with neuro-ophthalmic conditions, with either Goldmann or Octopus perimeters. However, meaningful differences exist between the two approaches with implications for consistency in longitudinal assessments.

\section{INTRODUCTION}

Neurological conditions in children can compromise the visual pathways and result in visual field (VF) changes with/without reduced visual acuity (VA) and/or impaired colour vision. ${ }^{1}$

There remains an incomplete evidence base regarding perimetry in the neuro-ophthalmological evaluation of children, ${ }^{2}$ reflecting the challenges of performing an intensive task, requiring prolonged, steady fixation and prompt responses. In children without ophthalmic conditions, variations exist by approach in the minimum age for reliable testing and ability to detect specific defects. ${ }^{3-11}$ Commonly, children with neuro-ophthalmic disease are assessed with kinetic perimetry to assess the full field, changes in VF shape/area, and delineate quadrant/hemifield defects whereas static perimetry has limited ability to detect subtle but important neuro-ophthalmic changes such as mild peripheral loss, slight nasal steps or subtle blind spot defects.

Goldmann perimetry is the established kinetic approach in children, but these perimeters are no longer commercially available. ${ }^{12}$ Proposed replacements (by Takagi and Inami) lack evidence to inform their use. However, Octopus perimeters are increasingly used in practice, adopting 'Goldmann equivalent' stimuli for kinetic perimetry, automated stimuli presentation, and drawing on normative data for interpreting outputs in children. ${ }^{13}$

To improve the evidence base for clinicians making decisions about perimetry in children with neuro-ophthalmic disease, we investigated differences between Goldmann and Octopus kinetic perimetry in the context of a wider research programme (the Optimal Perimetric Testing in Children study) by comparing feasibility, quality and outputs.

\section{METHODS}

We embedded this cross-sectional study within routine clinical care in our neuro-ophthalmology service at Great Ormond Street Hospital. Children aged 5-15 years, with either a diagnosed neuro-ophthalmic condition or known neuro-ophthalmic VF defect ${ }^{1}$ were included to capture this heterogeneous population. For ethical and data quality considerations, children unable to perform perimetry, because they were systemically unwell or unable to comprehend or cooperate for other reasons, were not included.

Potential participants were identified by examining medical records and were approached during their scheduled hospital visit. Children and their parents were given information sheets and opportunities to ask questions about the study. Parents/ guardians gave formal written consent, while children gave verbal assent.

VFs were measured using a Goldmann perimeter (Haag-Streit, Bern, Switzerland) and Octopus 900 (Haag-Streit) in a darkened clinic room, both by a single experienced orthoptist, who was unmasked to the participants' VF defect but had not previously tested them. 
To prioritise continuity of care, test order was not randomised. Thus, Goldmann perimetry was performed first, followed by a 5 min rest period before Octopus perimetry. The right eye was assessed first unless contraindicated clinically. Before each test participants were given standardised age-appropriate instructions regarding fixation and responding to stimuli, and tested their buzzer. ${ }^{14}$ After occlusion of one eye using a soft eye pad, they were aligned at the perimeter while sitting on a height adjustable chair.

Preparation time and any modifications necessary were recorded. Encouragement and repetition of instructions were given throughout. Rest breaks were offered and recorded if taken.

Refractive errors were corrected for isopter I2e only, ${ }^{15}$ if greater than +3.00 dioptre spheres (DS), greater than -1.00 DS, or greater than 1.00 dioptre cylinder. Where applicable, choice of isopters was based on previous Goldmann perimetry, with identical isopters selected for Octopus perimetry. Participants without prior experience were assessed using isopters $\mathrm{I} 4 \mathrm{e}$ and I2e. All tests started with plotting an outer, followed by inner isopter and then blind spot (I2e, stimulus speed of $2 \%$, allowing accustomisation with easier stimuli.

Targets were presented along 12 cardinal meridia (every $30^{\circ}$, at $5 \%$ s (automated for Octopus, approximated for Goldmann)), centripetally from a non-seeing area (manually defined start points), followed by further points, up to a maximum of 24 (ie, every $15^{\circ}$ ). For children with hemianopia, targets were presented centripetally for the seeing half of the field, but were presented every $15^{\circ}$ along the $y$-axis, from non-seeing to seeing areas, for the non-seeing field.

Quality of each test was assessed using the Examiner Based Assessment of Reliability (EBAR), ${ }^{14}$ which standardises the conventional qualitative clinical approach, taking account of comprehension of instructions, cooperation, fatigue, fixation and response to stimuli, to rate assessments as either 'good', 'fair' or 'poor' quality (online supplementary etable 1). We applied the quantitative kinetic perimetry reliability measure $(\mathrm{KPRM})^{16}$ of test-retest variability that uses the median value of the differences between four paired measurements: lower scores indicate better quality. Finally, children rated each test using a 5 -point Likert scale ranging from 'very hard' to 'very easy' and any additional comments were recorded.

Goldmann VF plots were digitised using Engauge Digitizer (open source, http://www.digitizer.sourceforge.net) and Goldmann and Octopus coordinates were extracted into matrices using the kineticF package ${ }^{17}$ in $\mathrm{R}$ (The R Project for Statistical Computing; V.3.2.0, http://www.r-project.org). VF defects were graded by the same unmasked clinician using the adaptation of Wall and George's ${ }^{18}$ classification system for children, but retaining information on blind spot defects. ${ }^{19}$ Higher scores represent greater VF loss from mild isopter constriction of less than $10^{\circ}$ (grade 1 ) to marked loss (grade 5 -isopter V4e within $20^{\circ}$ ). Type of VF defect was categorised and compared. ${ }^{20}$

\section{Statistical analysis}

Data were hosted securely in a Research Electronic Data Capture database $^{21}$ at UCL and exported to STATA (StataCorp, V.12) for analysis.

Analysis of feasibility draws on all participants. Statistical comparisons of outputs only use data from participants with 'good EBAR' scores for both tests, that is, tests deemed representative of a subject's true VF sensitivity. Comparisons of test duration used paired t-tests and agreement between isopter area from each perimeter was analysed by the Bland-Altman method. ${ }^{22}$ Agreement between VF loss severity scores was measured with linearly weighted kappa statistics (perfect agreement $=1$, with a decrease of 0.25 per level increase in disagreement). ${ }^{23}$ EBAR quality ratings were compared using McNemar's test. ${ }^{24}$

Multivariable linear regression models were fitted to investigate the relationship between test duration and age (continuous variable) including only factors significant at a 10\% level (two sided, $\mathrm{p}<0.1$ ) in univariable analyses, such as VA, isopter area (I4e), sex and ethnicity. Logistic regression models were fitted to investigate the relationship between EBAR and KPRM. Robust variance estimates were used to account for within-subject correlation (two eyes). ${ }^{25}$

\section{RESULTS}

Thirty of 31 (96.8\%) eligible children participated. The mean age of participants was 11.1 years (SD: 2.6), 12 (40\%) were female and 22 were White (73.3\%), with 3 Black, 4 Asian and 1 Mixed ethnicity child.

Twenty participants had prior experience of VF testing ranging from 1 to 8 years' experience (median=2 years (IQR: $1-3.5)$ ), with a median of 1.25 tests (IQR: $1-2.1$ ) per year. Median VA and spherical equivalent (averaged within subject, $\mathrm{n}=30$ ) was 0.04 LogMAR (IQR: $-0.08,0.21$ ) and 0.0 dioptre (IQR: 0.0, $0.56)$, respectively.

Table 1 lists for all 30 participants, diagnosis, type of VF defect recorded by Goldmann, and agreement with Octopus, and grade of VF loss for Goldmann and Octopus perimetry.

\section{Feasibility of perimetry}

One subject completed only Goldmann perimetry before withdrawing. Two children required rest breaks during Goldmann perimetry and were subsequently unable to complete Octopus perimetry. 27/30 participants (90\%) completed the Goldmann assessment in full, but in $3 / 30(10 \%)$ the blind spot could not be plotted due to poor cooperation. 22/29 (75.9\%) completed the Octopus assessment in full (table 2), but in 5, the blind spot could not be plotted due to poor cooperation. In one of these children a KPRM could not be plotted and in another testing was terminated due to fatigue. In addition, one child with Goldmann and two with Octopus perimetry had unreliable blind spot assessments. Thus, there were 4 (13\%) and 7 (24\%) either missing or unreliable blind spot plots for Goldmann and Octopus perimetry, respectively. Children with hemifield defects were noted to use intermittent search strategies to explore their non-seeing field.

Test duration was similar for both tests (t-test, $\mathrm{n}=29$, mean difference: $0.48 \min (-1.2,2.2), \mathrm{p}=0.559)$, and did not vary with increasing age for either Goldmann $(-0.02 \mathrm{~min} / \mathrm{year}$ $(-0.50,0.47), \mathrm{p}=0.939)$ or Octopus perimetry $(0.43(-0.19$, 1.04) $\mathrm{min} /$ year, $\mathrm{p}=0.164$ ) (table 2 ). Isopter area, VA, sex and ethnicity were not associated with test duration for either perimeter (univariable analyses).

\section{Quality of perimetry}

Quality ratings are shown in table 2 (Goldmann, $n=30$; Octopus, $n=29$ ). Failure to complete full testing was associated with poorer quality (ie, not 'good' EBAR) in 3/3 (100\%) children for Goldmann and 3/7 (43\%) children for Octopus perimetry-reflecting, for Octopus perimetry, the small number of otherwise cooperative children in whom the blind spot could not be plotted. 
Table 1 Neuro-ophthalmic diagnoses, associated visual field (VF) defects and grade of VF loss for all 30 participants, ordered by increasing severity of VF loss

\begin{tabular}{|c|c|c|c|c|c|c|}
\hline \multirow[b]{2}{*}{ Neuro-ophthalmic diagnosis } & \multirow[b]{2}{*}{ Age (years) } & \multirow[b]{2}{*}{ Eye } & \multirow[b]{2}{*}{ Visual field defect* } & \multirow{2}{*}{$\begin{array}{l}\text { Matching type } \\
\text { of VF defect? } ?^{20}\end{array}$} & \multicolumn{2}{|c|}{$\begin{array}{l}\text { Grade of visual field loss using the } \\
\text { modified Wall and George system }\end{array}$} \\
\hline & & & & & Goldmann & Octopus \\
\hline \multirow{2}{*}{$\begin{array}{l}\text { Idiopathic intracranial hypertension } \\
\text { (IIH) }\end{array}$} & \multirow[t]{2}{*}{7} & Right & Normal visual field & Yes & 0 & 0 \\
\hline & & Left & Normal visual field & Yes & 0 & 0 \\
\hline \multirow{2}{*}{$\begin{array}{l}\text { Suprasellar cyst } \\
\text { Hydrocephalus with VP shunt }\end{array}$} & \multirow[t]{2}{*}{7} & Right & Normal visual field & Yes & 0 & 0 \\
\hline & & Left & Normal visual field & Yes & 0 & 0 \\
\hline \multirow[t]{2}{*}{ Bilateral discrete white matter lesions } & \multirow[t]{2}{*}{7} & Right & $\begin{array}{l}\text { Normal visual field (previously found to have a } \\
\text { nasal step) }\end{array}$ & Yes & 0 & 0 \\
\hline & & Left & $\begin{array}{l}\text { Normal visual field (previously found to have a } \\
\text { nasal step) }\end{array}$ & Yes & 0 & 0 \\
\hline \multirow[t]{2}{*}{ Pituitary stalk lesion } & \multirow[t]{2}{*}{8} & Right & Normal visual field & Yes & 0 & 0 \\
\hline & & Left & Normal visual field & No & 0 & 1 \\
\hline \multirow{2}{*}{$\begin{array}{l}\text { Craniopharyngioma treated with cyst } \\
\text { decompression and photon therapy }\end{array}$} & \multirow[t]{2}{*}{14} & Right & Normal visual field & No & 0 & 1 \\
\hline & & Left & Normal visual field & No & 0 & 1 \\
\hline \multirow{2}{*}{$\begin{array}{l}\text { Langerhans cell histiocytosis with } \\
\text { lesions in the base of skull and orbits }\end{array}$} & \multirow[t]{2}{*}{12} & Right & Normal visual field & Yes & 0 & 0 \\
\hline & & Left & Enlarged blind spot & Yes & 1 & 1 \\
\hline \multirow{2}{*}{$\begin{array}{l}\text { Transverse myelitis with optic neuritis } \\
\text { and disc pallor }\end{array}$} & \multirow[t]{2}{*}{7} & Right & Normal visual field & No & 0 & 3 \\
\hline & & Left & Mild reduction in central visual field sensitivity & Yes & 1 & 2 \\
\hline \multirow{2}{*}{$\begin{array}{l}\text { Acute myeloid leukaemia (AML) and } \\
\text { BIH }\end{array}$} & \multirow[t]{2}{*}{12} & Right & Normal visual field & Yes & 0 & 0 \\
\hline & & Left & $\begin{array}{l}\text { Mild isopter constriction, with enlargement of the } \\
\text { blind spot }\end{array}$ & No & 1 & 0 \\
\hline \multirow[t]{2}{*}{$\mathrm{IIH}$} & \multirow[t]{2}{*}{11} & Right & Mild isopter constriction & No & 1 & 0 \\
\hline & & Left & Normal visual field & Yes & 0 & 0 \\
\hline Suprasellar epidermoid cyst & 11 & Right & Normal visual field & Yes & 0 & 0 \\
\hline & & Left & Small nasal step, with grossly enlarged blind spot & Yes & 2 & 2 \\
\hline $\begin{array}{l}\text { Craniopharyngioma treated with proton } \\
\text { beam therapy }\end{array}$ & 9 & Right & $\begin{array}{l}\text { Mild reduction in central visual field sensitivity, } \\
\text { with an enlarged blind spot }\end{array}$ & Yes & 1 & 1 \\
\hline & & Left & $\begin{array}{l}\text { Mild reduction in central visual field sensitivity, } \\
\text { with an enlarged blind spot }\end{array}$ & Yes & 1 & 1 \\
\hline Craniopharyngioma (partially resected) & 9 & Right & $\begin{array}{l}\text { Mild reduction in central visual field sensitivity, } \\
\text { with an enlarged blind spot }\end{array}$ & Yes & 1 & 1 \\
\hline & & Left & $\begin{array}{l}\text { Mild reduction in central visual field sensitivity, } \\
\text { with an enlarged blind spot }\end{array}$ & Yes & 1 & 1 \\
\hline Left optic nerve glioma & 12 & Right & Enlarged blind spot & Yes & 1 & 3 \\
\hline & & Left & $\begin{array}{l}\text { Mild isopter constriction, with an enlarged blind } \\
\text { spot }\end{array}$ & Yes & 1 & 2 \\
\hline $\mathrm{IIH}$ & 13 & Right & Mild isopter constriction & No & 1 & 1 \\
\hline & & Left & Mild isopter constriction & No & 1 & 1 \\
\hline Secondary raised intracranial pressure & 10 & Right & Mild reduction in central visual field sensitivity & NA & 1 & NA \\
\hline (ICP) after steroids & & Left & Mild isopter constriction (superior) & NA & 1 & NA \\
\hline Papilloedema & 5 & Right & Mild reduction in central visual field sensitivity & Yes & 1 & 1 \\
\hline & & Left & Mild reduction in central visual field sensitivity & NA & 1 & NA \\
\hline Pontine cavernoma & 11 & Right & Mild reduction in central visual field sensitivity & No & 1 & 0 \\
\hline & & Left & Mild reduction in central visual field sensitivity & No & 1 & 0 \\
\hline Low-grade glioma & 13 & Right & Enlarged blind spot & No & 1 & 0 \\
\hline & & Left & $\begin{array}{l}\text { Mild reduction in central visual field sensitivity, } \\
\text { with enlarged blind spot }\end{array}$ & No & 1 & 0 \\
\hline $\mathrm{IIH}$ & 14 & Right & $\begin{array}{l}\text { Moderate isopter constriction, with enlarged blind } \\
\text { spot }\end{array}$ & Yes & 1 & 2 \\
\hline & & Left & $\begin{array}{l}\text { Moderate isopter constriction, with enlarged blind } \\
\text { spot }\end{array}$ & Yes & 2 & 2 \\
\hline $\mathrm{IIH}$ & 14 & Right & $\begin{array}{l}\text { Moderate reduction in central visual field } \\
\text { sensitivity, with enlarged blind spot }\end{array}$ & Yes & 2 & 2 \\
\hline & & Left & $\begin{array}{l}\text { Moderate reduction in central visual field } \\
\text { sensitivity, with enlarged blind spot }\end{array}$ & Yes & 2 & 2 \\
\hline Right optic nerve glioma & 8 & Right & $\begin{array}{l}\text { Moderate isopter constriction (nasal step), with an } \\
\text { enlarged blind spot }\end{array}$ & Yes & 2 & 2 \\
\hline & & Left & Normal visual field & No & 0 & 1 \\
\hline
\end{tabular}


Table 1 Continued

\begin{tabular}{|c|c|c|c|c|c|c|}
\hline \multirow[b]{2}{*}{ Neuro-ophthalmic diagnosis } & \multirow[b]{2}{*}{ Age (years) } & \multirow[b]{2}{*}{ Eye } & \multirow[b]{2}{*}{ Visual field defect* } & \multirow{2}{*}{$\begin{array}{l}\text { Matching type } \\
\text { of VF defect? }\end{array}$} & \multicolumn{2}{|c|}{$\begin{array}{l}\text { Grade of visual field loss using the } \\
\text { modified Wall and George system }{ }^{18}\end{array}$} \\
\hline & & & & & Goldmann & Octopus \\
\hline \multirow[t]{2}{*}{ Chiari I malformation } & 10 & Right & $\begin{array}{l}\text { Moderate isopter constriction, with enlarged blind } \\
\text { spot }\end{array}$ & Yes & 3 & 3 \\
\hline & & Left & Mild isopter constriction, with enlarged blind spot & No & 1 & 0 \\
\hline \multirow[t]{2}{*}{ Medulloblastoma } & 10 & Right & $\begin{array}{l}\text { Mild/moderate isopter constriction, with isopter } \\
\text { I2e inside } 20^{\circ}\end{array}$ & Yes & 2 & 2 \\
\hline & & Left & Moderate isopter constriction, with a nasal step & Yes & 3 & 2 \\
\hline \multirow[t]{2}{*}{$\begin{array}{l}\text { Pilocytic brainstem astrocytoma with a } \\
\text { paramacular scar }\end{array}$} & 10 & Right & $\begin{array}{l}\text { Moderate isopter constriction, with isopter } 12 \mathrm{e} \\
\text { inside } 20^{\circ}\end{array}$ & Yes & 2 & 1 \\
\hline & & Left & $\begin{array}{l}\text { Moderate isopter constriction, with isopter I2e } \\
\text { inside } 20^{\circ}\end{array}$ & Yes & 2 & 2 \\
\hline \multirow[t]{2}{*}{$\begin{array}{l}\text { Posterior fossa astrocytoma (resected) } \\
\text { with a left IV cranial nerve palsy }\end{array}$} & 9 & Right & $\begin{array}{l}\text { Moderate isopter constriction, with isopter } 12 \mathrm{e} \\
\text { inside } 10^{\circ}\end{array}$ & No & 3 & 1 \\
\hline & & Left & $\begin{array}{l}\text { Moderate isopter constriction, with isopter } 12 \mathrm{e} \\
\text { inside } 20^{\circ}\end{array}$ & No & 2 & 1 \\
\hline \multirow[t]{2}{*}{$\begin{array}{l}\text { Arachnoid cyst—-tilted discs with } \\
\text { bilateral peripapillary atrophy }\end{array}$} & 9 & Right & $\begin{array}{l}\text { Moderate reduction in central visual field } \\
\text { sensitivity, with isopter } 12 \mathrm{e} \text { inside } 10^{\circ}\end{array}$ & Yes & 3 & 2 \\
\hline & & Left & $\begin{array}{l}\text { Moderate reduction in central visual field } \\
\text { sensitivity, with isopter } 12 \mathrm{e} \text { inside } 10^{\circ}\end{array}$ & Yes & 3 & 2 \\
\hline \multirow{2}{*}{$\begin{array}{l}\text { Grade I ganglioglioma (left cerebellum). } \\
\text { Posterior fossa craniotomy }\end{array}$} & 11 & Right & Moderate isopter constriction & Yes & 3 & 3 \\
\hline & & Left & $\begin{array}{l}\text { Moderate isopter constriction, with a right } \\
\text { hemifield defect }\end{array}$ & No & 4 & 3 \\
\hline \multirow{2}{*}{$\begin{array}{l}\text { Cervical meningocele with } \\
\text { hydrocephalus and Chiari II } \\
\text { malformation }\end{array}$} & 13 & Right & Severe isopter constriction & Yes & 4 & 4 \\
\hline & & Left & Severe isopter constriction & Yes & 4 & 4 \\
\hline \multirow[t]{2}{*}{ Epilepsy (lobectomy) } & 15 & Right & Right homonymous hemianopia & Yes & 4 & 4 \\
\hline & & Left & Right homonymous hemianopia & Yes & 4 & 4 \\
\hline \multirow[t]{2}{*}{ Glioma (occipital lobe high grade) } & 11 & Right & Left homonymous hemianopia & Yes & 4 & 4 \\
\hline & & Left & Left homonymous hemianopia & Yes & 4 & 4 \\
\hline
\end{tabular}

Shaded cells represent comparisons in those with good Examiner Based Assessment of Reliability (EBAR) ratings for Goldmann and Octopus perimetry ( $n=42$ ).

${ }^{*}$ As recorded with Goldmann perimetry.

$\mathrm{BIH}$, benign intracranial hypertension; NA, not applicable; VP, ventriculoperitoneal shunt.

Test quality (EBAR) was similar for Goldmann and Octopus perimetry for children $\geq 8$ years (McNemar's test, $\chi^{2}=1.0$, $\mathrm{p}=0.317)$. Children under 8 years demonstrated better quality results with Goldmann $(4 / 5,80 \%$ good EBAR) than Octopus perimetry $(2 / 5,40 \%$ good EBAR).

4/30 (13\%) and 10/29 (34\%) demonstrated fatigue during Goldmann and Octopus perimetry, respectively. 7/29 (24\%) children responded to the sound of stimulus presentation during Octopus perimetry, with $2 / 29$ children (6.9\%) sufficiently distracted to affect test quality.

The KPRM was implemented in 57/58 (98\%) eyes completing full testing. KPRM values increased (ie, worsened) with poorer test quality for Goldmann (adjusted OR: 4.0 (2.1, 5.9), good vs combined fair and poor quality), but not Octopus perimetry (1.4 $(-0.7,3.6), \mathrm{p}=0.178)$ (table 3$)$.

\section{Test outputs}

Goldmann and Octopus VF loss severity scores showed broad agreement $(\kappa=0.65 \quad(\mathrm{SE}=0.10), \mathrm{n}=21$, good 'EBAR' only, table 4). Scores were identical in $24 / 42$ tests (57\%) with $11 / 18$ (61.1\%) non-identical scores being lower (ie, less severe VF loss) for Octopus. All non-identical tests scored $\geq 2$ with Goldmann perimetry had a lower Octopus score but discordance was $>1$ in only $1 / 42(2.4 \%)$ test. Goldmann and Octopus outputs matched with respect to type of field defect in 29/42 (69\%) tests.

Table 2 Test feasibility and quality for Goldmann $(n=30)$ and Octopus perimetry $(n=29)$

\begin{tabular}{|c|c|c|c|c|c|c|c|c|c|c|}
\hline \multirow{3}{*}{$\begin{array}{l}\text { Age group } \\
\text { (years) }\end{array}$} & \multirow{2}{*}{\multicolumn{2}{|c|}{$\begin{array}{l}\text { Number completing } \\
\text { assessments (\%) }\end{array}$}} & \multirow{2}{*}{\multicolumn{2}{|c|}{$\begin{array}{l}\text { Median test duration* }(\mathrm{min}) \\
(\mathrm{IQR})\end{array}$}} & \multicolumn{6}{|c|}{ Test quality $\dagger$ (EBAR rating) (\%) } \\
\hline & & & & & \multicolumn{2}{|l|}{ Good } & \multicolumn{2}{|l|}{ Fair } & \multicolumn{2}{|l|}{ Poor } \\
\hline & Goldmann & Octopus & Goldmann & Octopus & Goldmann & Octopus & Goldmann & Octopus & Goldmann & Octopus \\
\hline $5-7(n=5)$ & $4(80)$ & $3(60)$ & $16(14,17)$ & $16(15,17)$ & $4(80)$ & $2(40)$ & $1(20)$ & $1(20)$ & 0 & $2(40)$ \\
\hline $8-11(n=15) \ddagger$ & $14(93.3)$ & $10(66.7)$ & $18(16,19)$ & $17(15,19)$ & $13(86.7)$ & $13(92.9)$ & $2(13.3)$ & $1(7.1)$ & 0 & 0 \\
\hline $12-15(n=10)$ & $9(90)$ & $9(90)$ & $17.5(16,19)$ & $18(15,19)$ & $7(70)$ & $7(70)$ & $2(20)$ & $3(30)$ & $1(10)$ & 0 \\
\hline All ages & $27 / 30(90)$ & $22 / 29(75.9)$ & $17(16,19)$ & $17(15,19)$ & $24 / 30(80)$ & $22 / 29(75.9)$ & $5 / 30(16.7)$ & $5 / 29(17.2)$ & $1 / 30(3.3)$ & $2 / 29(6.9)$ \\
\hline
\end{tabular}

*Test duration values include preparation and assessment tasks and include those children who failed to complete assessments

tTest quality ratings include those who failed to complete assessments in full.

$\ddagger \mathrm{n}=14$ for Octopus perimetry. 
Table 3 Median kinetic perimetry reliability measure (KPRM) values by EBAR quality scores for Goldmann and Octopus kinetic perimetry in all participants

\begin{tabular}{lll}
\hline \multirow{2}{*}{ EBAR rating } & \multicolumn{2}{l}{ Median KPRM (IQR) } \\
\cline { 2 - 3 } & Goldmann & Octopus \\
\hline Good & $1.8(1.2,3.8)$ & $2.7(2.2,4.3)$ \\
Fair & $7.4(4.6,9.1)$ & $4.5(3,7.4)$ \\
Poor & $6.8(5.4,8.3)^{*}$ & NAt \\
\hline
\end{tabular}

*Values indicate data range.

tThose with poor-quality Octopus results $(n=2)$ were unable to plot a KPRM.

EBAR, Examiner Based Assessment of Reliability; NA, not applicable.

On average, Octopus outputs depicted more extensive fields (ie, less VF loss); mean difference $-514.3 \mathrm{deg}^{2}$ (-817.4, $-211.2)$ and $-575.5 \mathrm{deg}^{2}(-900.1,-250.9)$ for isopters $\mathrm{I} 4 \mathrm{e}$ and I2e, respectively. On average, using Goldmann, blind spot area was $20.8 \mathrm{deg}^{2}(5.7,35.8)$ larger. Bland-Altman analysis (online supplementary efigure $1 \mathrm{~A}-\mathrm{C}$ ) showed modest agreement for the blind spot and smaller Goldmann area measures with both isopters, although limits of agreement were wide with increasing variation as average isopter area increased.

Blind spot size (using Goldmann perimetry) was larger for those with classification scores $\geq 1$ compared with those with score 0 (table 5).

\section{Self-report of examination experience}

Only two children reported Goldmann perimetry to be 'hard'. All other tests $(n=57)$ were scored as 'OK' (Goldmann, $n=11$ (41\%), Octopus, $\mathrm{n}=14$ (52\%)), 'easy’ (Goldmann, $\mathrm{n}=7$ (26\%), Octopus, $n=10(37 \%))$ or 'very easy' (Goldmann, $n=7$ (26\%), Octopus, $n=3(11 \%))$. Eight children preferred Octopus perimetry, citing newer/computerised technique, more reliable/ different buzzer, more visible stimuli $(n=3)$ and central fixation point $(n=2)$ and more comfortable chinrest.

\section{DISCUSSION}

We report a comparison of Goldmann and Octopus perimetry in children with diverse neuro-ophthalmic disorders, showing similar test duration for all ages, and similar quality in children over 8 years. Test quality did not improve with increasing age. Though both tests delineated neuro-ophthalmic VF defects, in many children neither the severity of VF loss nor type of defect depicted concorded between perimeters. Thus, although Goldmann and Octopus perimeters are similar in specification, their outputs are not directly interchangeable in this heterogeneous population.

\begin{tabular}{|c|c|c|c|c|c|c|}
\hline \multirow{2}{*}{$\begin{array}{l}\text { Goldmann } \\
\text { classification } \\
\text { score }\end{array}$} & \multicolumn{5}{|c|}{ Octopus classification score } & \multirow{2}{*}{$\begin{array}{l}\text { Total } \\
\text { eyes }\end{array}$} \\
\hline & 0 & 1 & 2 & 3 & 4 & \\
\hline 0 & 9 & 4 & 0 & 0 & 0 & 13 \\
\hline 1 & 6 & 5 & 1 & 0 & 0 & 12 \\
\hline 2 & 0 & 2 & 7 & 0 & 0 & 9 \\
\hline 3 & 0 & 1 & 3 & 1 & 0 & 5 \\
\hline 4 & 0 & 0 & 0 & 1 & 2 & 3 \\
\hline Total eyes & 15 & 12 & 11 & 2 & 2 & 42 \\
\hline
\end{tabular}

Shaded areas represent equivalent scores. Only participants who have 'good' Examiner Based Assessment of Reliability (EBAR) scores on both tests are shown here $(n=21)$.
Our study sample intentionally excluded children in whom formal perimetry would be precluded. Children were under active clinical monitoring, necessitating capturing of Goldmann perimetry and precluding test order randomisation which potentially introduced bias through fatigue and/or learning effects. However, quality ratings were only better for the first test in children under 8 years of age and test completion rates followed similar trends to those previously reported in children without ophthalmic disease (90\% vs $96.1 \%$ for Goldmann and $75.9 \%$ vs $89 \%$ for Octopus perimetry). ${ }^{14}$ A single examiner with expertise in perimetry undertook all the tests to avoid interexaminer variability. This examiner was unmasked to the participants' initial defect. Subsequent grading (as a separate exercise and without reviewing clinical details) of the recorded VF defects was also undertaken by one unmasked examiner using classification systems that do not include subjective interpretation.

We used the $\mathrm{EBAR}^{14}$ and $\mathrm{KPRM}^{16}$ metrics, our recently developed standardised measures of kinetic perimetry quality. EBAR scores show good agreement with static automated indices ${ }^{14}$ and KPRM ratings allow quantifiable documentation of test-retest variability, and thus aid interpretation of repeated testing over time. The ability to differentiate true change in VF sensitivity versus fluctuations in test quality is clinically significant: in the absence of automated reliability indices for kinetic perimetry, combined use of EBAR and KPRM scoring systems may help.

While complete agreement between Goldmann and Octopus perimetry regarding extent of VF loss may not be absolutely essential, our finding that Octopus perimetry may underestimate the most severe VF defects is important. Since differences between the two perimeters were also isopter sensitive, it is not recommended to use perimeters interchangeably when monitoring children longitudinally. Thus, if replacing Goldmann with Octopus perimetry, clinicians will need to develop appropriate strategies to transition patients, and interpret findings against perimeter-specific normative values. Further research is required to increase knowledge about monitoring progression with Octopus perimetry.

Inability to accurately plot blind spots was more common with Octopus perimetry even when far-peripheral testing was successful. Assessment of isolated blind spot defects can be of primary interest but also add nuanced interpretation of perimetry outputs.

Participants were less affected by the noise of Octopus perimetry than reported previously by children without field defects $(11 \% \text { vs } 6.9 \%)^{14}$ and commonly preferred Octopus perimetry. However, preference for test modality is not necessarily associated with better test quality. ${ }^{14}$ Contrary to findings in normative populations ${ }^{15}$ and children with glaucoma, ${ }^{26}$ test duration did not decrease with increasing age, possibly reflecting the challenges of assessing and characteristics of children with complex neurological conditions.

Our findings show the importance of stringent control of fixation, especially in patients with hemifield defects who have potential for recovery of field loss. ${ }^{27}$ Kinetic perimetry, pausing presentation of stimuli until fixation is restored, can improve accuracy of testing, mitigating fixation losses and search strategies.

There are no previous studies of conventional kinetic perimetry in a heterogeneous population of children with all-cause neuro-ophthalmic disease against which we can compare directly our findings. Early identification of VF loss is highly important but remains challenging in children in whom conventional perimetry is not possible, and for those too young to cooperate 
Table 5 Blind spot size for classification scores of 0 or higher in participants with 'good' quality tests

\begin{tabular}{|c|c|c|c|c|c|c|}
\hline & \multicolumn{3}{|c|}{ Goldmann classification score } & \multicolumn{3}{|c|}{ Octopus classification score } \\
\hline & Reference* & 0 & $\geq 1$ & Reference* & 0 & $\geq 1$ \\
\hline $\begin{array}{l}\text { Median blind spot size } \\
\left(\text { deg }^{2}\right)(\text { (IQR) }\end{array}$ & $\begin{array}{l}76.4 \\
(61.4,94.7)\end{array}$ & $\begin{array}{l}84.5 \\
(72.6,94.3)\end{array}$ & $\begin{array}{l}113.6 \\
(86.2,147.7)\end{array}$ & $\begin{array}{l}60.8 \\
(41.9,80.6)\end{array}$ & $\begin{array}{l}79 \\
(68,97.5)\end{array}$ & $\begin{array}{l}75.5 \\
(53.9,135.5)\end{array}$ \\
\hline
\end{tabular}

${ }^{*}$ Reference values are based on age-appropriate normative data. ${ }^{13}$

with testing. Attention needs to be directed to developing and refining approaches which allow early detection of gross defects including approaches that are showing promise in the evaluation of young children. ${ }^{28-30}$ Non-quantifiable or suprathreshold tests have merit in this regard but are limited with respect to their ability to act as a 'baseline' assessment for monitoring progressive VF loss in those who can be expected to be able to perform full formal perimetry later in childhood. We suggest future research should be directed at identifying the elements of kinetic perimetry with greatest diagnostic value in specific conditions, to develop disorder-specific protocols that maximise utility while minimising burden of testing. Our generic findings should inform the design of such research.

Static perimetry has poor sensitivity for detecting subtle peripheral neuro-ophthalmic defects. ${ }^{31}$ Large defects should be detectable by static perimetry, though limited evidence exists about the effect of algorithm 'optimisation' for glaucoma, and thus we suggest kinetic perimetry is preferable for neuro-ophthalmic defects of any severity. ${ }^{32}$

Our findings in a heterogeneous group of children with neuro-ophthalmic disease able to cooperate with formal testing support attempting either Octopus or Goldmann kinetic perimetry in children $\geq 8$ years of age, with the expectation of meaningful outputs in most. However, clinicians should be mindful that outputs are not directly interchangeable, and that differences are greatest with the most severe VF loss, with implications for transitioning from Goldmann to Octopus perimeters.

Acknowledgements We are grateful to Haag-Streit (Switzerland) for the loan of an Octopus perimeter to Great Ormond Street Hospital for this study.

Collaborators OPTIC study group members: Peng Tee Khaw, PhD, FRCOphth (NIHR BRC MEH/UCL IOO); Bronwen Walters, BMedSci (GOSH): Phillippa M Cumberland, BA, MSC (UCL GOS ICH, UVRG); Isabelle Russell-Eggitt, FRCOphth (UVRG); Chris Timms, DBO(T) (MEH); John Brookes, BSc, FRCOphth (MEH, GOSH); Anthony Moore, FRCOphth, FMedSci (UCL IOO/MEH, University of California); Maria Papadopoulos, FRCOphth (MEH); David Garway-Heath, MD, FRCOphth (NIHR BRC MEH/UCL IOO); Ananth Viswanathan, PhD, FRCOphth (MEH); Alki Liasis, PhD (GOSH); David Crabb, MSc, PhD (City University); Mario Cortina-Borja, MSc, PhD (UCL GOS ICH); Dipesh E Patel, BMedSci, PhD (UCL GOS ICH/GOSH, MEH); and Jugnoo S Rahi, PhD, FRCOphth (UCL GOS ICH/GOSH, UCL IOO/MEH).

Contributors Concept and design: DEP, PMC, BCW, JSR. Acquisition, analysis or interpretation of data: all authors. Drafting of the manuscript: DEP. Critical revision of the manuscript for important intellectual content: all authors. Statistical analysis: DEP, PMC, MCB. Obtained funding: BCW, PMC, JSR. Administrative, technical or material support: DEP, JSR. Supervision: PMC, BCW, MCB, JSR. Final approval of the article: all authors.

Funding This work was supported by The Guide Dogs for the Blind Association (GBDA) (grant number OR2009-04e). This research was supported by the National Institute for Health Research (NIHR) Biomedical Research Centre based at Moorfields Eye Hospital NHS Foundation Trust/UCL Institute of Ophthalmology and UCL GOS Institute of Child Health/Great Ormond Street Hospital NHS Foundation Trust. JSR is part funded by the National Institute for Health Research, Biomedical Research Centre based at Moorfields Eye Hospital NHS Foundation Trust and UCL Institute of Ophthalmology. JSR is a National Institute for Health Research (NIHR) senior investigator. PMC is funded by the Ulverscroft Foundation.

Disclaimer The sponsor and funding organisation had no role in the design and conduct of the study; collection, management, analysis and interpretation of data; preparation, review or approval of the manuscript; and decision to submit the manuscript for publication. The views expressed are those of the authors and not necessarily those of the NHS, the NIHR or the Department of Health.

Competing interests None declared.

Patient consent Not required.

Ethics approval The National Health Service Research Ethics Committee for London-Bloomsbury approved the study which followed the tenets of the Declaration of Helsinki.

Provenance and peer review Not commissioned; externally peer reviewed. Open access id='9860a03e-5ec9-4ccd-9daf-c8f0b704a463'>

\section{REFERENCES}

1 Harbert MJ, Yeh-Nayre LA, O'Halloran HS, et al. Unrecognized visual field deficits in children with primary central nervous system brain tumors. J Neurooncol 2012;107:545-9.

2 RCPCH. Brain tumours - pathways to diagnosis: the diagnosis of brain tumours. http:// www.rcpch.ac.uk/child-health/standards-care/child-health-guidelines-and-standards/ guidelines-endorsed-rcpch-subsp-14

3 Wabbels BK, Wilscher S. Feasibility and outcome of automated static perimetry in children using continuous light increment perimetry (CLIP) and fast threshold strategy. Acta Ophthalmo/ Scand 2005;83:664-9.

4 Wilscher S, Wabbels B, Lorenz B. Feasibility and outcome of automated kinetic perimetry in children. Graefes Arch Clin Exp Ophthalmol 2010;248:1493-500.

5 Bjerre A, Codina C, Griffiths H. Peripheral visual fields in children and young adults using semi-automated kinetic perimetry: feasibility of testing, normative data, and repeatability. Neuroophthalmology 2014;38:189-98.

6 Akar Y, Yilmaz A, Yucel I. Assessment of an effective visual field testing strategy for a normal pediatric population. Ophthalmologica 2008;222:329-33.

7 Tschopp C, Safran AB, Viviani P, et al. Automated visual field examination in children aged $5-8$ years. Part I: experimental validation of a testing procedure. Vision Res 1998;38:2203-10

8 Tschopp C, Safran AB, Viviani P, et al. Automated visual field examination in children aged 5-8 years. Part II: normative values. Vision Res 1998;38:2211-8.

9 Martin L. Rarebit and frequency-doubling technology perimetry in children and young adults. Acta Ophthalmo/ Scand 2005;83:670-7

10 Quinn GE, Fea AM, Minguini N. Visual fields in 4- to 10-year-old children using Goldmann and double-arc perimeters. J Pediatr Ophthalmol Strabismus 1991:28:314-9.

11 Wilson M, Quinn G, Dobson V, et al. Normative values for visual fields in 4- to 12-year-old children using kinetic perimetry. J Pediatr Ophthalmol Strabismus 1991;28:151-3.

12 Walters BC, Rahi JS, Cumberland PM. Perimetry in children: survey of current practices in the United Kingdom and Ireland. Ophthalmic Epidemiol 2012;19:358-63.

13 Patel DE, Cumberland PM, Walters BC, et al. Study of Optimal Perimetric Testing In Children (OPTIC): normative visual field values in children. Ophthalmology 2015;122:1711-7

14 Patel DE, Cumberland PM, Walters BC, et al. Study of Optimal Perimetric Testing in Children (OPTIC): feasibility, reliability and repeatability of perimetry in children. PLOS One 2015:10:e0130895.

15 Henson D, Fields V. Visual fields. 2nd edn. Butterworth-Heinemann, 2000.

16 Patel DE, Viswanathan AC, Garway-Heath D, et al. Study of Optimal Perimetric Testing In Children (OPTIC): development and feasibility of the kinetic perimetry reliability measure (KPRM). Br J Ophthalmol 2017;101:94-6.

17 Patel DE, Cortina-Borja M. kineticF: framework for the analysis of kinetic visual field data, R package version 1.0. The Comprehensive R Archive Network 2015.

18 Wall M, George D. Idiopathic intracranial hypertension. A prospective study of 50 patients. Brain 1991;114:155-80.

19 Liasis A, Walters B, Thompson D, et al. Visual field loss in children with craniosynostosis. Childs Nerv Syst 2011;27:1289-96.

20 Rowe FJ, Rowlands A. Comparison of diagnostic accuracy between Octopus 900 and Goldmann kinetic visual fields. Biomed Res Int 2014;2014:1-11.

21 Harris PA, Taylor R, Thielke R, et al. Research electronic data capture (REDCap)--a metadata-driven methodology and workflow process for providing translational research informatics support. J Biomed Inform 2009;42:377-81. 
22 Bland JM, Altman DG. Statistical methods for assessing agreement between two methods of clinical measurement. Lancet 1986;1:307-10.

23 Landis JR, Koch GG. The measurement of observer agreement for categorical data. Biometrics 1977:33:159-74.

24 Mantel N, Fleiss JL. The equivalence of the generalized McNemar tests for marginal homogeneity in 2(3) and 3(2) tables. Biometrics 1975;31:727-9.

25 Rogers WH. Regression standard errors in clustered samples. Stata Technical Bulletin 1993:13:19-23.

26 Patel DE, Cumberland PM, Walters BC, et al. Comparison of quality and output of different optimal perimetric testing approaches in children with glaucoma. JAMA Ophthalmol 2018;136:155-61.

27 Handley SE, Vargha-Khadem F, Bowman RJ, et al. Visual function 20 years after childhood hemispherectomy for intractable epilepsy. Am J Ophthalmol 2017;177:81-9.
28 Koenraads $Y$, Braun $K P$, van der Linden DC, et al. Perimetry in young and neurologically impaired children: the Behavioral Visual Field (BEFIE) Screening Test revisited. JAMA Ophthalmol 2015;133:319-25.

29 Murray IC, Fleck BW, Brash HM, et al. Feasibility of saccadic vector optokinetic perimetry: a method of automated static perimetry for children using eye tracking. Ophthalmology 2009;116:2017-26.

30 Mayer DL, Fulton AB, Cummings MF. Visual fields of infants assessed with a new perimetric technique. Invest Ophthalmol Vis Sci 1988:29:452.

31 Rowe FJ, Cheyne CP, García-Fiñana M, et al. Detection of visual field loss in pituitary disease: peripheral kinetic versus central static. Neuroophthalmology 2015:39:116-24.

32 Duncan JE, Freedman SF, El-Dairi MA. The incidence of neovascular membranes and visual field defects from optic nerve head drusen in children. J Aapos 2016;20:44-8 